\title{
Optimizing management of advanced urothelial carcinoma: A review of emerging therapies and biomarker-driven patient selection
}

Peter C. Black ${ }^{1}$; Nimira S. Alimohamed ${ }^{2}$; David Berman ${ }^{3}$; Normand Blais ${ }^{4}$; Bernhard Eigl ${ }^{5}$; Pierre I. Karakiewicz ${ }^{6}$; Wassim Kassouf ${ }^{7}$; Girish S. Kulkarni ${ }^{8}$; Michael Ong ${ }^{9}$; Alan Spatz ${ }^{10}$; Srikala S. Sridhar ${ }^{11}$; Tracy Stockley ${ }^{12}$; Theodorus van der Kwast ${ }^{13}$; Huong Hew ${ }^{14}$; Laura ParkWyllie $^{14}$; Scott A. North ${ }^{15}$

${ }^{1}$ Department of Urologic Sciences, University of British, Columbia, Vancouver, BC, Canada; ${ }^{2}$ Tom Baker Cancer Centre, Calgary, AB, Canada; ${ }^{3}$ Queen's Cancer Research Institute, Kingston, ON, Canada; ${ }^{4}$ Division of Medical Oncology/Hematology, Centre hospitalier de l'Université de Montréal, Montreal, QC, Canada; ${ }^{5}$ [insert]; ${ }^{6}$ Service d'urologie, Centre hospitalier de l'Université de Montréal, Montreal, QC, Canada; ${ }^{7}$ Department of Urology, McGill University Health Centre, Montreal, QC, Canada; ${ }^{8}$ Departments of Surgery (Urology), Princess Margaret Cancer Centre and the University Health Network, University of Toronto, Toronto, ON, Canada; ${ }^{9}$ Division of Medical Oncology, University of Ottawa, Ottawa, ON, Canada; ${ }^{10}$ Departments of Pathology and Oncology at McGill University, Montreal, QC, Canada; ${ }^{11}$ Departments of Medical Oncology, Princess Margaret Cancer Centre and the University Health Network, University of Toronto, Toronto, ON, Canada; ${ }^{12}$ Department of Clinical Laboratory Genetics, University Health Network, Toronto, ON, Canada; ${ }^{13}$ Department of Pathology, University Health Network, Toronto, ON, Canada; ${ }^{14}$ Medical Affairs, Janssen Inc, Toronto, ON, Canada; ${ }^{15}$ Division of Medical Oncology, University of Alberta, Edmonton, AB, Canada

ICMJE Disclaimer: This article was prepared according to ICMJE recommendations. Medical writing assistance was provided by Precision-Rx-Dx Inc. Janssen Canada supported the development of the algorithm, provided funding for medical writing services and their employees were contributing authors.

Acknowledgements: The authors would like to thank Janssen Canada for funding this initiative, the Precision Rx-Dx Inc team for assistance with the working group, Philippa Bridge-Cook, PhD, of Precision Rx-Dx Inc for medical writing services, and Noumeira Hamoud, PhD, of Janssen Canada for helping to coordinate the manuscript submission

Cite as: Can Urol Assoc J 2020 March 23; Epub ahead of print. http://dx.doi.org/10.5489/cuaj.6458

Published online March 23, 2020

$* * *$

\section{Abstract}

Introduction: Advanced urothelial carcinoma has been challenging to treat due to limited treatment options, poor response rates, and poor long-term survival. New treatment options hold the promise of improved outcomes for these patients.

Methods: A multidisciplinary working group drafted a management algorithm for advanced urothelial carcinoma using "consensus development conference" methodology. A targeted 
literature search identified new and emerging treatments for inclusion in the management algorithm. Published clinical data were considered during the algorithm development process, as well as the risks and benefits of the treatment options. Biomarkers to guide patient selection in clinical trials for new treatments were incorporated into the algorithm.

Results: The advanced urothelial carcinoma management algorithm includes newly approved first-line anti- programmed death receptor-1 (PD1)/ programmed death-ligand 1 (PD-L1) therapies, a newly approved anti- fibroblast growth factor receptors (FGFR) therapy, and an emerging anti-Nectin 4 therapy, which have had encouraging results in phase 2 trials for secondline and third-line therapy, respectively. This algorithm also incorporates suggestions for biomarker testing of PD-L1 expression and FGFR gene alterations.

Conclusions: Newly approved and emerging therapies are starting to cover an unmet need for more treatment options, better response rates, and improved overall survival in advanced urothelial carcinoma. The management algorithm provides guidance on how to incorporate these new options, and their associated biomarkers, into clinical practice.

\section{Introduction}

Urothelial carcinoma is a significant cause of cancer-related morbidity and mortality in Canada: it is the fourth most commonly diagnosed cancer in men and is expected to account for 11,800 new cases, and 2,500 deaths in 2019. ${ }^{1}$ About $25 \%$ of patients present with muscle invasive disease, are at high risk for recurrence and metastasis, and have guarded long term survival rates of $36 \%$ for regional disease, and 5\% for metastatic disease. ${ }^{2,3}$ Platinum-based chemotherapy has traditionally been the first line treatment for unresectable locally advanced or metastatic urothelial carcinoma; however, the median overall survival (OS) with gemcitabine and cisplatin is only 12-15 months, and a five-year survival of only $15 \%$. $^{4-6}$

Few therapeutic options were available for second-line metastatic urothelial carcinoma until recently. Between 2017 and early 2018, four immune checkpoint inhibitors-pembrolizumab, atezolizumab, durvalumab and avelumab--were approved in Canada for patients with locally advanced or metastatic urothelial carcinoma with disease progression during or following platinum-containing chemotherapy or disease progression within 12 months of neoadjuvant or adjuvant platinum-based chemotherapy. Pembrolizumab is associated with an approximately three month survival advantage over chemotherapy in the second-line setting with a median OS of 10.3 months compared to 7.4 months on chemotherapy (HR $0.73,95 \%$ CI 0.59 0.91, $\mathrm{p}=0.002$ ). Response rates for immune checkpoint inhibitors in general are relatively low but durable: approximately 13 to $24 \%$ of patients respond..$^{7-12}$

New therapeutic options are on the horizon, with positive phase 2 clinical trial results published recently for erdafitinib and enfortumab vedotin. ${ }^{13,14}$ Erdafitinib is a tyrosine kinase inhibitor of fibroblast growth factor receptors 1 to 4 (FGFR 1-4). Mutations and fusions in FGFR 
2 and 3 are found in approximately $20 \%$ of patients with invasive urothelial carcinoma and result in constitutive FGFR signalling that can lead to carcinogenesis. ${ }^{15,16}$ Erdafitinib received Breakthrough Therapy designation from the U.S. Food and Drug Administration (FDA) in March 2018, accelerated approval from the FDA in April 2019, and Notice of Compliance with Condition to complete phase 3 studies from Health Canada in October 2019, for the treatment of adults with locally advanced or metastatic urothelial carcinoma which is characterized by susceptible FGFR 2 or 3 genetic alterations, and who have progressed after at least one line of platinum-containing chemotherapy. Enfortumab vedotin is an emerging therapy that received Breakthrough Therapy designation from the FDA in March 2018 and was FDA-approved in December 2019 for the treatment of adult patients with locally advanced or metastatic urothelial cancer who have previously received a programmed death receptor-1 (PD-1) or programmed death-ligand 1 (PD-L1) inhibitor, and a platinum-containing chemotherapy in the neoadjuvant/adjuvant, locally advanced or metastatic setting. It is an antibody-drug conjugate consisting of a monoclonal antibody directed against Nectin-4, conjugated to a microtubuledisrupting agent. ${ }^{17}$ This is the first agent targeting Nectin-4, which is expressed on many solid tumours, including urothelial carcinoma.

With the introduction of these new therapeutics comes the urgent need for biomarker testing to help guide treatment selection and sequencing of drugs. In first-line treatment, cisplatin-ineligible but carboplatin-eligible patients may be selected for anti-PD-L1 therapy rather than carboplatin-based chemotherapy by testing tumour tissue for PD-L1 expression levels. ${ }^{18}$ FGFR-targeted therapy will be administered only to patients with altered FGFR2 or FGFR3 in tumour tissue. Nectin-4 is expressed on virtually all advanced urothelial carcinoma so that use of enfortumab vedotin is not dependent on a biomarker.

With new advances in treatment options in the metastatic setting and increasing use of biomarker-driven patient selection, guidance is required to help clinicians understand how to incorporate new treatment options and required biomarker testing to optimize management of urothelial carcinoma. A national multidisciplinary working group was convened to develop a management algorithm and practice guidance to help clinicians understand the potential place in therapy for new agents and optimal use and timing of biomarker testing.

\section{Methods}

\section{Algorithm development}

A multidisciplinary national working group was formed to develop a management algorithm for advanced urothelial carcinoma. This group had pan-Canadian representation and included medical oncologists, urologic-oncologists, pathologists, and laboratory medicine specialists. The working group began by reviewing an established bladder cancer care pathway ${ }^{19}$ and subsequently incorporated emerging treatments and predictive biomarkers according to scientific evidence and anticipated approvals. Emerging treatments were included if phase 2 clinical trial 
data had been published by July 2019 or an Investigational New Drug (IND) submission had been posted on the Health Canada website by July 2019 (anticipated approval by July 2020). Inclusion of predictive biomarkers was restricted to biomarkers that had been used to guide patient selection in clinical trials for emerging treatments as described above. The group discussion considered all of the published evidence available supporting the new therapies, as well as their benefits and risks for patients. In areas with limited published evidence, expert opinion was considered along with the published evidence, and the level of evidence used have been described throughout. The algorithm assumes that patient inclusion in clinical trials and best supportive care are options at any stage of treatment for advanced bladder cancer. Treatment choices supported by phase 3 data were preferred where possible, although the group supported a model that allows for clinical judgement to be used to determine the best course of action for an individual patient. The working group was divided into two subgroups - treatment and testing to separately draft management algorithms in an iterative fashion through initial virtual meetings. The treatment subgroup focused on optimal use of current and emerging treatments, while the testing subgroup focused on the integration of predictive biomarkers. The full group was subsequently assembled to review both algorithms and develop a final management algorithm using a 'consensus development conference' methodology. ${ }^{20}$

\section{Literature search}

A targeted literature search was performed to identify primary reports of phase 2 or 3 clinical trials of therapies for unresectable locally advanced or metastatic urothelial carcinoma. In order to update a previously developed management algorithm, the literature search focused on publications that appeared in MEDLINE $®$ between the dates of January 1, 2017 (the year prior to publication of a previous management algorithm ${ }^{18}$ ) and July 31, 2019. Treatments that had favourable efficacy and safety profiles from full clinical trial analyses were included in the new management algorithm; treatments that only had interim or preliminary results published were excluded.

\section{Results and discussion}

The management of urothelial carcinoma is a rapidly evolving area. Guidelines for currently approved therapies were recently published ${ }^{21}$ however, since that publication, additional therapies have already been approved for new indications within the metastatic setting, ${ }^{18}$ and further new therapies are expected to be approved over the next year.

\section{Literature search results}

The targeted literature search revealed that pembrolizumab and atezolizumab published phase 3 trials in the second line setting and phase 2 trials in the first line setting for cisplatin-ineligible patients. ${ }^{7-12}$ Additional data in the second line setting have been published with avelumab, durvalumab, and erdafitinib. ${ }^{10,12,13}$ Phase 2 data with enfortumab vedotin data in the third line 
setting have also been published. ${ }^{14}$ Although phase 2 data were also published with nivolumab in the second line setting, it was excluded from consideration for inclusion in the algorithm because, unlike the other second line immunotherapy agents, it is not approved by Health Canada. ${ }^{22}$ Infigratinib (BGJ398) is a fibroblast growth factor receptor inhibitor that has been shown to have encouraging efficacy in a phase 1 expansion study (NCT01004224) in 67 patients with advanced urothelial carcinoma, but it is not included in the algorithm because no results are available from Phase 2 or Phase 3 studies. Rogaratinib is at a similar stage of clinical development. ${ }^{23}$

\section{Summary of clinical data for new and emerging therapies}

KEYNOTE-052 and IMvigor-210 examined pembrolizumab and atezolizumab, respectively, in patients ineligible for cisplatin chemotherapy (Table 1). ${ }^{7,8}$ The objective response rate (ORR) was $24 \%$ for pembrolizumab and $23 \%$ for atezolizumab. Responses were seen regardless of PD-L1 expression levels, although an increased ORR was observed in patients with high PD-L1 expression when treated with pembrolizumab. The median duration of response was not reached in either study, although the available data indicated that the duration of responses was longer than for chemotherapy. The safety profiles of both agents were acceptable, with reversible immune-mediated toxicity occurring in about 10 to $20 \%$ of patients. ${ }^{18}$ The initial FDA approvals for these agents were subsequently revised based on unpublished early review of data from the respective ongoing phase 3 trials which suggested that patients with low levels of PD-L1 expression had decreased survival with pembrolizumab or atezolizumab monotherapy compared to patients receiving platinum-based chemotherapy. Subsequent publication of results with first line atezolizumab demonstrated that the overall survival curves converged after approximately 12 months. ${ }^{24}$ The FDA approvals for pembrolizumab and atezolizumab, and the Health Canada approval for pembrolizumab, are now restricted to patients ineligible for any platinum-containing chemotherapy regardless of PD-L1 expression levels, and for patients who are cisplatin-ineligible but eligible for carboplatin chemotherapy with high PD-L1 expression levels. ${ }^{18}$

Four immunotherapies have been approved in Canada as second line therapy. Of these, pembrolizumab and atezolizmab are currently the only two with published phase 3 trial results, KEYNOTE-045 and IMvigor-211 respectively. Of these two trials, KEYNOTE-045 was the only one to demonstrate a significant difference in overall survival for immunotherapy compared to chemotherapy, by approximately three months. ${ }^{9}$ This survival benefit was seen in the total population, not selected by PD-L1 expression level, as well as in the high PD-L1-expression subgroup. In addition, immunotherapy had a better safety profile than chemotherapy in both trials. ${ }^{9,11}$ For the four available second line immunotherapy agents, ORR varied from $13 \%$ to $21 \%$ (Table 2). Results from phase 2 clinical trials for these agents varied in whether PD-L1/PD-1 expression levels predicted for increased efficacy, although all four therapies did show efficacy regardless of expression levels. ${ }^{9-12}$

Phase 2 clinical trials reported objective response rates of $40 \%$ for erdafitinib and $44 \%$ for enfortumab vedotin, ${ }^{13,14}$ and other key clinical trial readouts are summarized in Tables 2 and 3. In 
the erdafitinib phase 2 trial, patients with pre-defined $F G F R$ gene alterations were enrolled after at least one prior course of chemotherapy. Treatment-related adverse events grade 3 or higher occurred in $46 \%$ of patients, and included hyponatremia, stomatitis, asthenia, and more rarely, hyperphosphatemia, as a frequent but low grade adverse event that allows titration of erdafitinib dose. ${ }^{13}$ The enfortumab vedotin phase 2 trial enrolled patients previously treated with both platinum chemotherapy and immunotherapy. Treatment-related adverse events grade 3 or higher occurred in $54 \%$ of patients, and included fatigue, rash, and peripheral sensory neuropathy. ${ }^{14}$

\section{Algorithm for management of advanced urothelial carcinoma}

The management algorithm is shown in Figure 1. The algorithm begins at the point of transurethral resection of a bladder tumour (TURBT) to encompass the optimal timing of biomarker testing, which commonly uses radical cystectomy specimens or occasionally archival TURBT specimens or bladder biopsies. The primary focus of the algorithm was to support treatment and decision-making in the locally advanced or metastatic urothelial carcinoma setting (hereafter referred to as advanced urothelial carcinoma).

\section{Management of muscle invasive urothelial carcinoma}

Diagnosis and management of urothelial carcinoma starts with TURBT (Figure 1). Traditionally, radical cystectomy has been the cornerstone of early management of muscle-invasive disease ${ }^{25}$ however, some patients may receive bladder sparing management, consisting of trimodality therapy (TMT): TURBT, chemotherapy for radiation sensitization, and external beam radiotherapy. ${ }^{26}$ Neoadjuvant chemotherapy should be offered to eligible patients before radical cystectomy, and should be considered before TMT. ${ }^{27}$ Patients who have residual or recurrent muscle-invasive bladder cancer (MIBC) after TMT should undergo cystectomy, if they are fit for the procedure. ${ }^{27}$

\section{PD-L1 reflex testing}

The working group recommends that reflex testing for PD-L1 expression should be performed in patients with adverse pathological features at cystectomy as these patients are most likely to recur and require downstream systemic therapies. This test can be done easily in the context of the existing pathology workflow, without significantly increasing the cost or complexity. Adverse features that would trigger reflex testing include one or more of the following: pathologic stage T2 after prior neoadjuvant chemotherapy, pathologic stage T3 or T4, lymph node involvement, lymphovascular invasion, and positive surgical margins. It is therefore important to provide information on prior systemic treatment to the pathologist to assist in decision making regarding reflex testing. Cystectomy specimens are preferred for reflex testing due to the amount of tissue, quality of sample, and the representativeness of the sample, over TURBT specimens. There are limited data on the value of retesting PD-L1 expression from a new biopsy at the time of 
progression; therefore, retesting is not recommended at this time. ${ }^{28-30}$ Additional aspects of PDL1 testing such as assay harmonization are discussed in more detail below.

\section{First-line treatment of metastatic urothelial carcinoma}

For patients whose disease recurs or progresses, or who present with de novo metastatic urothelial carcinoma, first line treatment is determined by cisplatin eligibility and PD-L1 expression levels (Figure 1). The recommended initial regimen in patients who are eligible for cisplatin treatment is cisplatin and gemcitabine. Cisplatin eligibility criteria were evaluated by Galsky et al. and are continuing to evolve. ${ }^{31}$ Patients with recurrence less than 12 months from prior perioperative chemotherapy treatment usually proceed straight to second line treatment options. Individuals with predominantly locally advanced disease who had a good response to first line systemic therapy may benefit from consolidation with radiotherapy or surgery. The working group recommends that patients who are cisplatin ineligible but carboplatin-eligible may receive either gemcitabine plus carboplatin doublet therapy or approved immune-oncology therapy (IO), provided testing results show high PD-L1 expression, as defined in the clinical trial for each therapy. ${ }^{7,8}$ Patients who are ineligible for platinum chemotherapy may receive immunotherapy regardless of PD-L1 expression level.

\section{FGFR gene alteration testing}

The working group identified the initiation of first-line therapy as a clinical trigger point to test for FGFR gene alterations. The group discussed that they viewed this similarly to reflex testing, except in this case, physicians would use a clinical point as the trigger for testing rather than a specific test result as a trigger. Waiting to test for FGFR alterations until later in disease, such as once a patient has disease progression on first-line therapy and contemplating second-line options, was felt likely to cause delay of subsequent $2 \mathrm{~L}$ treatment. Once a patient is initiating first-line therapy, it is understood that most patients will progress to second-line therapy. Rationale for this timing of the FGFR gene alteration testing is discussed in more detail below.

\section{Second-line treatment and beyond}

With chemotherapy as the standard of care for treatment of first-line advanced urothelial carcinoma, phase 3 evidence supports sequencing on disease progression from chemotherapy to immunotherapy (Figure 1). ${ }^{32}$ Four anti-PD-L1/PD-1 therapies (pembrolizumab, atezolizumab, avelumab, and durvalumab) are currently approved by Health Canada for this setting. Treatment with erdafitinib also represents an option for patients with FGFR gene alterations who have progressed on first or second-line therapy. In the near future, enfortumab vedotin may also represent an option for patients who have progressed on prior chemotherapy and immunotherapy. Taxane chemotherapy may also be used as salvage chemotherapy. ${ }^{5}$ The working group supported having multiple treatment options accessible for second line therapy which would allow clinicians to discuss available options with their patients and individualize therapy. 


\section{Considerations for individualizing treatment}

A number of factors are often considered when selecting a second line treatment to individualize therapy for the patient. These may include level of evidence, clinical trial characteristics of the treatment options, disease volume/characteristics, contraindications, toxicity profiles, route of administration, time to response, and regional funding criteria (Table 4). Prior therapies received by the patient will also play a role in choosing a second line therapy. Physicians should understand their regional funding criteria in order to optimize their available treatment options. Patient preferences may also influence the choice of treatment, although patient education is important to ensure that patients are making informed choices and have reasonable expectations regarding side effects, response rate, and time to response.

\section{Immunotherapy}

In the second-line setting, immunotherapy is indicated in patients who have received prior platinum therapy based on Phase 3 data. This higher level of evidence should influence the selection of pembrolizumab over erdafitinib. The working group felt that it is rare to have absolute contraindications to immunotherapy and these drugs are generally well tolerated. However, a minority of patients may experience major toxicities that require intervention, and treatment of patients with history of autoimmune disease should be done carefully and selectively. A minority of patients develop significant immune-related adverse events which require monitoring. A significant proportion of patients do not respond to immunotherapy; however, in patients who do respond, many achieve durable responses. Immunotherapy usually requires intravenous administration every 2-3 weeks until disease progression or unmanageable toxicity.

\section{Erdafitinib}

In the second-line setting, erdafitinib has been approved in platinum-pretreated patients based on phase 2 data. The working group discussed that erdafitinib as an oral agent might be appealing to patients as an alternative to intravenous therapy and could be an important option for patients who live in remote areas or where travelling to the hospital is an issue. Initiation of erdafitinib will require a baseline opthalmologic visit and dose titration according to serum phosphate levels. Hyperphosphatemia is a known side effect of FGFR inhibitors and occurred in $77 \%$ of patients. Ocular events are also an expected side effect with this class of therapies, and occurred in $21 \%$ of patients, with most events being grade 2 or lower, and resolving with dose interruption or reduction. Nail and skin events occurred in $49 \%$ and $52 \%$ of patients respectively, with most events being grade 2 or lower. $13 \%$ of patients discontinued treatment because of treatmentrelated adverse events. ${ }^{13}$

It remains controversial whether patients with $F G F R$ gene alterations are less likely to respond to immunotherapy. FGFR3 alterations are common in luminal papillary tumors, which are characterized by an immune-excluded or immune desert phenotype, that would suggest that 
these tumors may be less likely respond to checkpoint blockade. This is corroborated by early data from second line trials with atezolizumab (IMvigor210) and nivolumab (Checkmate 275), but further investigation is needed. ${ }^{8,33}$ On the other hand, Wang et al recently reported that the presence of FGFR alterations did not correlate to outcome in either IMvigor210 or Keynote045 (pembrolizumab). ${ }^{34}$ In the phase 2 clinical trial of erdafitinib, 22 patients had received prior immunotherapy and the confirmed response rate to erdafitinib among those patients was 59\%, while the prior response to immunotherapy in those patients was $5 \% .{ }^{13}$ Similar findings of responses to an FGFR inhibitor in patients who had not previously responded to immunotherapy were seen in an early report from a phase 1 trial of rogaratinib. ${ }^{35}$ However, in both trials patients were selected due to progression on prior therapy, and these trials do not reveal the likelihood of a patient with FGFR3 alteration responding to immunotherapy.

\section{Enfortumab vedotin (EV)}

In the third-line setting, EV has been approved in the US in the post-platinum, postimmunotherapy setting based on Phase 2 data, and is expected to be approved for the same indication in Canada. Physicians will therefore have to decide between erdafintib or EV in this setting, although ideally it would be possible to treat with both sequentially. EV is given by intravenous administration on days 1, 8 and 15 of every 28 -day cycle. As Nectin- 4 was detected in all patients tested in the phase 2 trial, biomarker testing is not needed for treatment with EV. Peripheral neuropathy is a known toxicity with this type of agent and occurred in $50 \%$ of patients. Most occurrences were grade 2 or less, and most had resolved or had grade 1 peripheral neuropathy at last follow-up. Rash was an anticipated on-target toxicity and occurred in $48 \%$ of patients, with $75 \%$ being grade 2 or less. Treatment-related hyperglycemia occurred in $11 \%$ of patients, regardless of known hyperglycemia at baseline. Treatment-related adverse events led to discontinuation in $12 \%$ of patients. ${ }^{14}$

\section{Considerations regarding biomarker testing for advanced bladder cancer}

\section{PD-L1 immunohistochemistry testing}

In addition to reflex testing of PD-L1 in high risk cystectomy patients, in some cases the physician will need to order a PD-L1 test if testing did not occur as a reflex test such as high-risk TMT patients and de-novo metastatic patients.

Different in vitro diagnostic assays (IVDs) have been developed as companion diagnostics for different anti-PD-L1 therapies, and laboratories may also choose to use a laboratory-developed test. For the purpose of testing PD-L1 status in urothelial carcinoma, any validated test can be used as long as the assay provides results that are concordant with the approved companion diagnostic tested in clinical trials; $;^{7,10-12,36}$ that is, the assay should provide the same classification of patients by PD-L1 expression levels as in those trials. Harmonization between laboratories and 
standardization of how PD-L1 testing results are reported in urothelial carcinoma will be required.

\section{FGFR gene alteration testing}

Testing for FGFR gene alterations prior to initiating first-line treatment for advanced urothelial carcinoma will need to be requisitioned by the treating physician. Because prior neoadjuvant therapy may influence diagnostic interpretation and the assessment of risk variables, the requisition should state what prior therapy the patient has had, what other testing has been done, and to whom/where the report should be sent; the latter is important to avoid delays. However, unlike for the PD-L1 IHC assay, the working group recommended against having the FGFR gene alteration testing performed on a reflex basis for patients with adverse pathologic features in the cystectomy specimen because, in contrast to immunotherapy, erdafitinib will only be used in the second line, and there is adequate time to test it if ordered at the time of initiating first line therapy. In addition, limited data suggest that FGFR gene alterations are stable over time. ${ }^{37}$ Later testing will be associated with significant cost savings especially with the higher cost of this type of testing compared to IHC testing for PD-L1 expression. Of all patients receiving first line treatment, approximately $46 \%$ will go on to receive second line treatment. ${ }^{38} \mathrm{~A}$ two-week turnaround time between specimen reception at the test center and report signing out was defined as the standard benchmark adequate for FGFR gene alteration testing.

FGFR gene alteration testing will likely be done by next-generation sequencing (NGS), due to the ability to test multiple genes and mutation types simultaneously on NGS. The test will make use of archived cystectomy specimens if available, and otherwise TUR or biopsy specimens. When sending tissue for FGFR gene alteration testing, a representative formalin-fixed paraffin-embedded (FFPE) block is preferred, but unstained slides may also be accepted. Pathologists from the holding lab should request the specimen requirements from the testing lab the samples will be sent to. The working group recommended that in cystectomy specimens the pathologist should designate a block that should be maintained in the pathology lab for all future molecular testing in order to ensure that the tissue is not exhausted for research or other endeavours. In addition, the pathologist can mark the slides that are optimal for molecular testing. The importance of sending tissue quickly when the test is requisitioned should be stressed to the referring lab. FGFR gene alteration testing performed on circulating tumour DNA (ctDNA) from plasma samples has potential clinical utility however, due its relatively low sensitivity, it should be reserved for cases in which diagnostic tissue is not available. ${ }^{39,40}$

\section{Limitations of this work}

Rapid advances in this therapeutic area will likely lead to the approval of new therapies and potentially new biomarkers, and the algorithm described herein will need to be revisited at regular intervals to incorporate these advances. The timing of biomarker testing as delineated in the algorithm is based on expert opinion only, which may be the cause for some debate. Some of 
the recommended therapies lack high level evidence because they are supported only by single arm trials. We anticipate that the level of evidence supporting the newer therapies and their sequencing in the algorithm will continue to evolve.

\section{Future directions in metastatic urothelial carcinoma}

Results of several ongoing phase 2 and phase 3 trials are anticipated over the next few years and these trials will provide additional results to guide the treatment of metastatic urothelial carcinoma. Phase 3 trials of immunotherapy compared to chemotherapy in the first line setting are ongoing (NCT02853305, NCT02807636), as well as phase 3 trials of erdafitinib (NCT03390504) and enfortumab vedotin (NCT03474107). Combination therapies are being investigated, in addition to new agents such as novel FGFR inhibitors and immunotherapies. In addition, research into predictive biomarkers is ongoing. Deficiencies in DNA damage repair genes, tumour mutational burden, and microsatellite instability are examples of biomarkers under investigation to predict response to immune checkpoint inhibitors, and targetable genetic alterations such as EGFR, ERBB2, ERBB3, PIK3CA and RAS have been found as likely oncogenic drivers of subsets of bladder cancers. ${ }^{41}$ New therapeutic options and the potential for additional biomarkers to guide patient selection are likely to reshape the treatment landscape for advanced bladder cancer in the near future. 


\section{Summary of key points}

\section{Treatment of advanced urothelial carcinoma}

- First-line therapy

- Gemcitabine + cisplatin remains the standard treatment (Phase 3 evidence)

- Gemcitabine + Carboplatin can be used in patients deemed unfit for cisplatin

- Patients ineligible for cisplatin now also have the option of using immunotherapy according to Health Canada criteria (Non-randomized phase 2 evidence)

- Second-line and third-line therapy

- Immunotherapy is recommended for patients who progressed on prior chemotherapy (Phase 3 evidence).

- Taxane-based chemotherapy may be used

- Anti-FGFR therapy may be considered as an alternative in patients with FGFR alterations who progressed on prior chemotherapy or immunotherapy (Phase 2 evidence).

- Pending Health Canada approval, enfortumab vedotin may be considered in patients who have progressed on prior chemotherapy and immunotherapy (Phase 2 evidence).

- Optimal sequencing of treatment in second-line is not known at this time based on the current data. Clinical judgement should be used to determine the best course of action for an individual patient.

Biomarker Testing for advanced urothelial carcinoma

- PD-L1 expression levels should be performed as a reflex test in patients with adverse pathological features at cystectomy in order to have results available when the patient needs $1 \mathrm{~L}$ treatment if progression occurs.

- FGFR gene alteration testing should be requisitioned/triggered by a patient's initiation of first-line therapy for advanced urothelial carcinoma in order to have results available when the patient needs $2 \mathrm{~L}$ treatment 


\section{References}

1. Canadian Cancer Statistic Advisory Committee. Canadian Cancer Statistics 2019. Toronto, ON: Canadian Cancer Society; 2019.

2. Aragon-Ching JB, Werntz RP, Zietman AL, Steinberg GD. Multidisciplinary Management of Muscle-Invasive Bladder Cancer: Current Challenges and Future Directions. Am Soc Clin Oncol Educ Book 2018;38:307-18.

3. Survival Rates for Bladder Cancer. American Cancer Society, 2020. (Accessed February 26, 2020, 2020, at https://www.cancer.org/cancer/bladder-cancer/detection-diagnosisstaging/survival-rates.html.)

4. Choueiri TK, Ross RW, Jacobus S, et al. Double-blind, randomized trial of docetaxel plus vandetanib versus docetaxel plus placebo in platinum-pretreated metastatic urothelial cancer. J Clin Oncol 2012;30:507-12.

5. Lalani AA, Sonpavde GP. Systemic treatments for metastatic urothelial carcinoma. Expert Opin Pharmacother 2019;20:201-8.

6. von der Maase H, Sengelov L, Roberts JT, et al. Long-term survival results of a randomized trial comparing gemcitabine plus cisplatin, with methotrexate, vinblastine, doxorubicin, plus cisplatin in patients with bladder cancer. J Clin Oncol 2005;23:4602-8.

7. Balar AV, Castellano D, O'Donnell PH, et al. First-line pembrolizumab in cisplatinineligible patients with locally advanced and unresectable or metastatic urothelial cancer (KEYNOTE-052): a multicentre, single-arm, phase 2 study. Lancet Oncol 2017;18:148392.

8. Balar AV, Galsky MD, Rosenberg JE, et al. Atezolizumab as first-line treatment in cisplatin-ineligible patients with locally advanced and metastatic urothelial carcinoma: a single-arm, multicentre, phase 2 trial. Lancet 2017;389:67-76.

9. Bellmunt J, de Wit R, Vaughn DJ, et al. Pembrolizumab as Second-Line Therapy for Advanced Urothelial Carcinoma. N Engl J Med 2017;376:1015-26.

10. Patel MR, Ellerton J, Infante JR, et al. Avelumab in metastatic urothelial carcinoma after platinum failure (JAVELIN Solid Tumor): pooled results from two expansion cohorts of an open-label, phase 1 trial. Lancet Oncol 2018;19:51-64.

11. Powles T, Duran I, van der Heijden MS, et al. Atezolizumab versus chemotherapy in patients with platinum-treated locally advanced or metastatic urothelial carcinoma (IMvigor211): a multicentre, open-label, phase 3 randomised controlled trial. Lancet 2018;391:748-57.

12. Powles T, O'Donnell PH, Massard C, et al. Efficacy and Safety of Durvalumab in Locally Advanced or Metastatic Urothelial Carcinoma: Updated Results From a Phase 1/2 Openlabel Study. JAMA Oncol 2017;3:e172411. 
13. Loriot Y, Necchi A, Park SH, et al. Erdafitinib in Locally Advanced or Metastatic Urothelial Carcinoma. N Engl J Med 2019;381:338-48.

14. Rosenberg JE, O'Donnell PH, Balar AV, et al. Pivotal Trial of Enfortumab Vedotin in Urothelial Carcinoma After Platinum and Anti-Programmed Death 1/Programmed Death Ligand 1 Therapy. J Clin Oncol 2019:JCO1901140.

15. Karkera JD, Cardona GM, Bell K, et al. Oncogenic Characterization and Pharmacologic Sensitivity of Activating Fibroblast Growth Factor Receptor (FGFR) Genetic Alterations to the Selective FGFR Inhibitor Erdafitinib. Mol Cancer Ther 2017;16:1717-26.

16. Perera TPS, Jovcheva E, Mevellec L, et al. Discovery and Pharmacological Characterization of JNJ-42756493 (Erdafitinib), a Functionally Selective Small-Molecule FGFR Family Inhibitor. Mol Cancer Ther 2017;16:1010-20.

17. Challita-Eid PM, Satpayev D, Yang P, et al. Enfortumab Vedotin Antibody-Drug Conjugate Targeting Nectin-4 Is a Highly Potent Therapeutic Agent in Multiple Preclinical Cancer Models. Cancer Res 2016;76:3003-13.

18. Suzman DL, Agrawal S, Ning YM, et al. FDA Approval Summary: Atezolizumab or Pembrolizumab for the Treatment of Patients with Advanced Urothelial Carcinoma Ineligible for Cisplatin-Containing Chemotherapy. Oncologist 2019;24:563-9.

19. Bladder Cancer Diagnosis, Treatment and Follow-up Care Pathway Map. Cancer Care Ontario, 2018. (Accessed August 21, 2019, at https://www.cancercareontario.ca/sites/ccocancercare/files/assets/CCOBladderPathwayM ap.pdf.)

20. WHO Handbook for Guideline Development. In: Lauckner M, ed. 2nd ed. Geneva: World Health Organization; 2014.

21. Warren M, Kolinsky M, Canil CM, et al. Canadian Urological Association/Genitourinary Medical Oncologists of Canada consensus statement: Management of unresectable locally advanced and metastatic urothelial carcinoma. Can Urol Assoc J 2019:318-27.

22. Sharma P, Siefker-Radtke A, de Braud F, et al. Nivolumab Alone and With Ipilimumab in Previously Treated Metastatic Urothelial Carcinoma: CheckMate 032 Nivolumab $1 \mathrm{mg} / \mathrm{kg}$ Plus Ipilimumab 3 mg/kg Expansion Cohort Results. J Clin Oncol 2019;37:1608-16.

23. Schuler M, Cho BC, Sayehli CM, et al. Rogaratinib in patients with advanced cancers selected by FGFR mRNA expression: a phase 1 dose-escalation and dose-expansion study. Lancet Oncol 2019;20:1454-66.

24. Grande E, Galsky MD, Arija JAA, et al. IMvigor130: a phase III study of atezolizumab with or without platinum based chemotherapy in previously untreated metastatic urothelial carcinoma. European Society for Medical Oncology. Barcelona2019.

25. Shariat SF, Karakiewicz PI, Palapattu GS, et al. Outcomes of radical cystectomy for transitional cell carcinoma of the bladder: a contemporary series from the Bladder Cancer Research Consortium. J Urol 2006;176:2414-22; discussion 22. 
26. Wettstein MS, Rooprai JK, Pazhepurackel C, et al. Systematic review and meta-analysis on trimodal therapy versus radical cystectomy for muscle-invasive bladder cancer: Does the current quality of evidence justify definitive conclusions? PLoS One 2019; 14:e0216255.

27. Chang SS, Bochner BH, Chou R, et al. Treatment of Non-Metastatic Muscle-Invasive Bladder Cancer: AUA/ASCO/ASTRO/SUO Guideline. J Urol 2017;198:552-9.

28. Melosky B, Blais N, Cheema P, et al. Standardizing biomarker testing for Canadian patients with advanced lung cancer. Curr Oncol 2018;25:73-82.

29. Tretiakova M, Fulton R, Kocherginsky M, et al. Concordance study of PD-L1 expression in primary and metastatic bladder carcinomas: comparison of four commonly used antibodies and RNA expression. Mod Pathol 2018;31:623-32.

30. Wang H, Agulnik J, Kasymjanova G, et al. The metastatic site does not influence PD-L1 expression in advanced non-small cell lung carcinoma. Lung Cancer 2019;132:36-8.

31. Galsky MD, Hahn NM, Rosenberg J, et al. A consensus definition of patients with metastatic urothelial carcinoma who are unfit for cisplatin-based chemotherapy. Lancet Oncol 2011;12:211-4.

32. Fradet Y, Bellmunt J, Vaughn DJ, et al. Randomized phase III KEYNOTE-045 trial of pembrolizumab versus paclitaxel, docetaxel, or vinflunine in recurrent advanced urothelial cancer: results of $>2$ years of follow-up. Ann Oncol 2019.

33. Ohyama C, Kojima T, Kondo T, et al. Nivolumab in patients with unresectable locally advanced or metastatic urothelial carcinoma: CheckMate 275 2-year global and Japanese patient population analyses. Int J Clin Oncol 2019.

34. Wang L, Gong Y, Saci A, et al. Fibroblast Growth Factor Receptor 3 Alterations and Response to PD-1/PD-L1 Blockade in Patients with Metastatic Urothelial Cancer. Eur Urol 2019;76:599-603.

35. Joerger M, Cassier PA, Penel N, et al. Rogaratinib in patients with advanced urothelial carcinomas prescreened for tumor FGFR mRNA expression and effects of mutations in the FGFR signaling pathway. J Clin Oncol 2018;36:4513-.

36. Bellmunt J, Powles T, Vogelzang NJ. A review on the evolution of PD-1/PD-L1 immunotherapy for bladder cancer: The future is now. Cancer Treat Rev 2017;54:58-67.

37. Turo R, Harnden P, Thygesen H, et al. FGFR3 expression in primary invasive bladder cancers and matched lymph node metastases. J Urol 2015;193:325-30.

38. Kamat AM, Cao X, He J, Zhong Y, Shah AY, Flannery K. Costs of Care for Patients Receiving Chemotherapy for Advanced Bladder Cancer. Journal Clin Pathways 2017;3:63-70.

39. Santiago-Walker A, Moy C, Cherkas Y, et al. Analysis of FGFR alterations from circulating tumor DNA (ctDNA) and Tissue in a phase II trial of erdafitinib in urothelial carcinoma (UC). J Clin Oncol 2019;37:420. 
40. Tan MP, Attard G, Huddart RA. Circulating Tumour DNA in Muscle-Invasive Bladder Cancer. Int J Mol Sci 2018;19.

41. Yoshida T, Kates M, Fujita K, Bivalacqua TJ, McConkey DJ. Predictive biomarkers for drug response in bladder cancer. Int J Urol 2019;26:1044-53.

42. AstraZeneca Canada Inc. Product Monograph: Imfinzi. AstraZeneca CAnada Inc; 2019.

43. EMD Serono. Product Monograph: Bavencio. EMD Inc; 2019.

44. Hoffman-La Roche Limited. Product Monograph: Tecentriq. Hoffman-La Roche Limited; 2019.

45. Merck Canada. Product Monograph: Keytruda. Merck Sharp \& Dohme Inc; 2019. 


\section{Figures and Tables}

Fig. 1. Algorithm for management of advanced urothelial carcinoma.

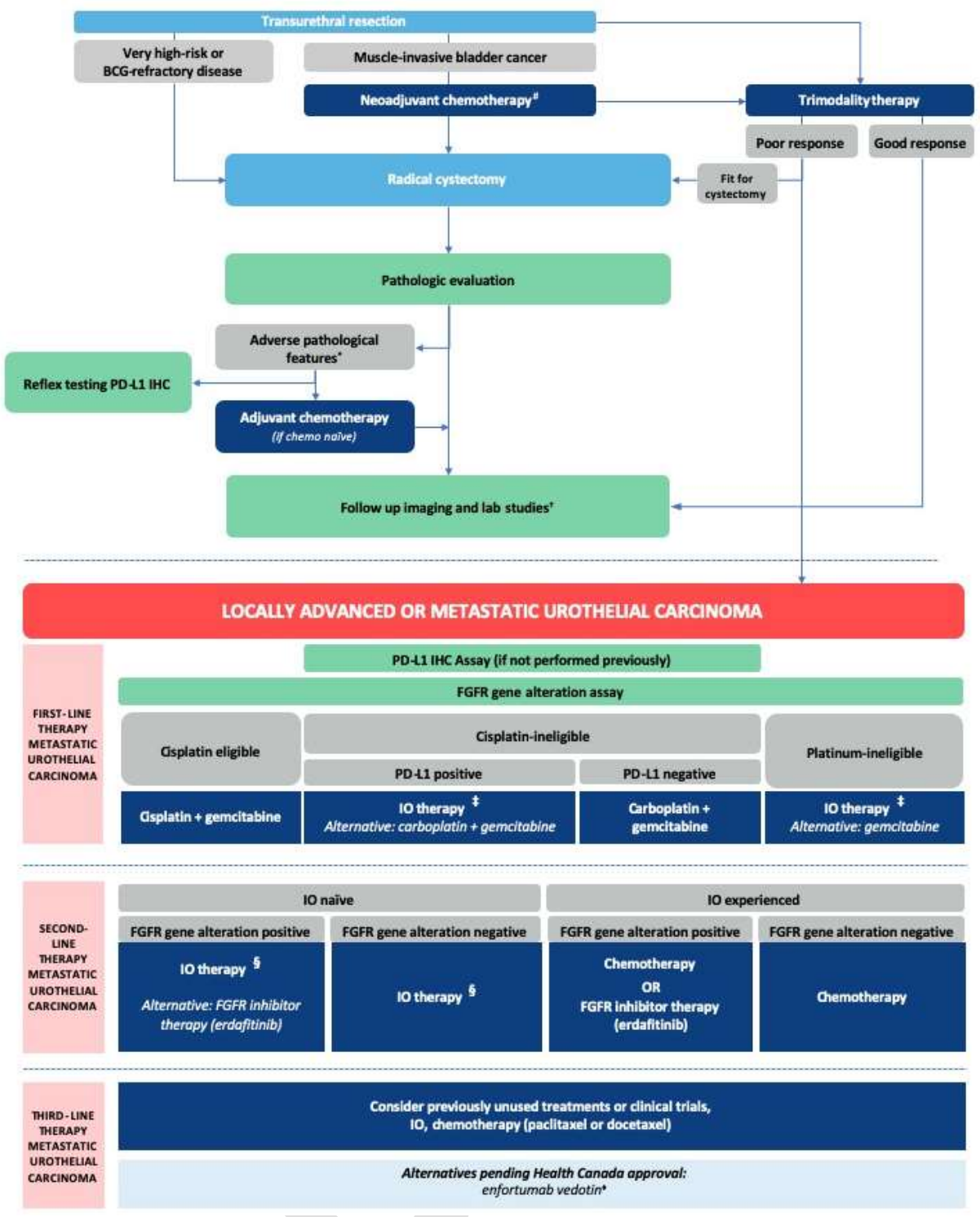

\# If patients are fit for cisplatin-based neoadjuvant chemotherapy. *Adverse pathological features include lymph node metastases, lymphovascular invasion, positive surgical margins, pathological T3/T4, consider for patients T2. ${ }^{\dagger}$ Followup imaging and lab studies at 3, 6, 12, 18, 24, 36, 48 and 60 months. Imaging modalities, frequency is dependent upon pathological stage. Followup after 5 years without recurrence depends on shared decision making between the specialist and patient. ${ }^{19}$ $\$$ Approved for $1 \mathrm{~L}$. ${ }^{\S}$ Approved for $2 \mathrm{~L}$. Enfortumab vedotin anticipated approval is for postchemo/post IO therapy. BCG: bacillus Calmette-Guerin; FGFR: fibroblast growth factor receptor; IHC: immunohistochemistry; IO: immuno-oncology; MIBC: muscle-invasive bladder cancer; PD-L1: programmed death ligand 1; TUR: transurethral resection. 


\begin{tabular}{|l|c|c|c|c|c|c|}
\hline $\begin{array}{l}\text { Table 1. New first line treatments for advanced urothelial carcinoma in the cisplatin - } \\
\text { ineligible setting }\end{array}$ & $\begin{array}{c}\text { Study } \\
\text { design } \\
\text { Drug name }\end{array}$ & $\begin{array}{c}\text { Overall } \\
\text { survival }\end{array}$ & $\begin{array}{c}\text { Median } \\
\text { PFS }\end{array}$ & $\begin{array}{c}\text { Objective } \\
\text { response } \\
\text { rate }\end{array}$ & $\begin{array}{c}\text { Median } \\
\text { time to } \\
\text { response }\end{array}$ & $\begin{array}{c}\text { Median } \\
\text { duration } \\
\text { of } \\
\text { response }\end{array}$ \\
\hline $\begin{array}{l}\text { Pembrolizumab } \\
\text { KEYNOTE-052 }\end{array}$ & $\begin{array}{c}\text { Single-arm, } \\
\text { multicenter } \\
\text { phase 2 } \\
\text { study }\end{array}$ & $\begin{array}{c}67 \% \text { at } 6 \\
\text { months }\end{array}$ & $\begin{array}{c}30 \% \text { at } 6 \\
\text { months }\end{array}$ & $24 \%$ & 2.0 & $\begin{array}{c}\text { Not } \\
\text { reached } \\
\text { (median } \\
\text { followup } \\
\text { months) }\end{array}$ \\
\hline $\begin{array}{l}\text { IMvigor 210 } \\
\text { Cohort 1 }\end{array}$ & $\begin{array}{c}\text { Single-arm, } \\
\text { multicenter } \\
\text { phase 2 } \\
\text { study }\end{array}$ & $\begin{array}{c}\text { Median: } \\
\text { months }\end{array}$ & $\begin{array}{c}2.7 \\
\text { months }\end{array}$ & $23 \%$ & $\begin{array}{c}\text { Not } \\
\text { months }\end{array}$ & $\begin{array}{c}\text { reached } \\
\text { (median } \\
\text { followup } \\
17.2 \\
\text { months) }\end{array}$ \\
\hline
\end{tabular}

PFS: progression-free survival. 


\begin{tabular}{|c|c|c|c|c|c|c|}
\hline Drug name & $\begin{array}{l}\text { Study } \\
\text { design }\end{array}$ & $\begin{array}{c}\text { Median } \\
\text { overall } \\
\text { survival }\end{array}$ & $\begin{array}{c}\text { Median } \\
\text { PFS }\end{array}$ & $\begin{array}{c}\text { Objective } \\
\text { response } \\
\text { rate }\end{array}$ & $\begin{array}{c}\text { Median } \\
\text { time to } \\
\text { respons } \\
\text { e }\end{array}$ & $\begin{array}{c}\text { Median } \\
\text { duration } \\
\text { of } \\
\text { response }\end{array}$ \\
\hline Pembrolizumab & $\begin{array}{l}\text { Randomized, } \\
\text { open-label, } \\
\text { international } \\
\text { phase } 3 \\
\text { study } 9\end{array}$ & $\begin{array}{c}10.3 \\
\text { months }\end{array}$ & $\begin{array}{c}2.1 \\
\text { months }\end{array}$ & $21.1 \%$ & $\begin{array}{c}2.1 \\
\text { months }\end{array}$ & $\begin{array}{c}\text { Not } \\
\text { reached } \\
\text { (median } \\
\text { followup } \\
14.1 \\
\text { months) }\end{array}$ \\
\hline Atezolizumab & $\begin{array}{c}\text { Randomized, } \\
\text { open-label, } \\
\text { multicenter } \\
\text { phase } 3 \\
\text { study }^{11} \\
\end{array}$ & $\begin{array}{c}39.2 \% \text { at } \\
12 \\
\text { months }\end{array}$ & $\begin{array}{c}2.1 \\
\text { months }\end{array}$ & $13.4 \%$ & $\begin{array}{c}\text { Not } \\
\text { reported }\end{array}$ & $\begin{array}{c}21.7 \\
\text { months }\end{array}$ \\
\hline Avelumab & $\begin{array}{c}\text { Open label, } \\
\text { single-arm, } \\
\text { multicenter } \\
\text { dose- } \\
\text { escalation } \\
\text { phase } 1 \\
\text { trial }^{10}\end{array}$ & $\begin{array}{c}6.5 \\
\text { months }\end{array}$ & $\begin{array}{c}1.4 \\
\text { months }\end{array}$ & $17 \%$ & $\begin{array}{c}11.4 \\
\text { weeks }\end{array}$ & $\begin{array}{c}\text { Not } \\
\text { reached } \\
\text { (median } \\
\text { followup } \\
9.9 \\
\text { months) }\end{array}$ \\
\hline Durvalumab & $\begin{array}{c}\text { Open-label, } \\
\text { single-arm } \\
\text { phase } 1 / 2 \\
\text { study }^{12}\end{array}$ & $\begin{array}{c}18.2 \\
\text { months }\end{array}$ & $\begin{array}{c}1.5 \\
\text { months }\end{array}$ & $17.8 \%$ & $\begin{array}{c}1.4 \\
\text { months }\end{array}$ & $\begin{array}{c}\text { Not } \\
\text { reached } \\
\text { (median } \\
\text { followup } \\
5.8 \\
\text { months) }\end{array}$ \\
\hline Erdafitinib & $\begin{array}{l}\text { Two-arm }{ }^{*} \text {, } \\
\text { multicenter, } \\
\text { open-label } \\
\text { phase } 2 \\
\text { study }^{13}\end{array}$ & $\begin{array}{c}13.8 \\
\text { months }\end{array}$ & $\begin{array}{c}5.5 \\
\text { months }\end{array}$ & $40 \%$ & $\begin{array}{c}1.4 \\
\text { months }\end{array}$ & $\begin{array}{c}5.6 \\
\text { months }\end{array}$ \\
\hline
\end{tabular}

*Each arm used a different dosing and administration schedule. PFS: progression-free survival. 


\begin{tabular}{|c|c|c|c|c|c|c|c|}
\hline Drug name & $\begin{array}{l}\text { Study } \\
\text { design }\end{array}$ & $\begin{array}{c}\text { Patient } \\
\text { population }\end{array}$ & $\begin{array}{c}\text { Median } \\
\text { overall } \\
\text { survival }\end{array}$ & $\begin{array}{l}\text { Median } \\
\text { PFS }\end{array}$ & $\begin{array}{c}\text { Objective } \\
\text { response } \\
\text { rate }\end{array}$ & $\begin{array}{l}\text { Median } \\
\text { time to } \\
\text { response }\end{array}$ & $\begin{array}{c}\text { Median } \\
\text { duration of } \\
\text { response }\end{array}$ \\
\hline $\begin{array}{l}\text { Enfortumab } \\
\text { vedotin } \\
\text { EV-201 }\end{array}$ & $\begin{array}{l}\text { Single-arm, } \\
\text { open-label, } \\
\text { multi- } \\
\text { cohort, } \\
\text { phase } 2 \\
\text { multicenter } \\
\text { study }^{14}\end{array}$ & $\begin{array}{l}\text { Patients with } \\
\text { locally } \\
\text { advanced or } \\
\text { metastatic } \\
\text { urothelial } \\
\text { cancer who } \\
\text { previously } \\
\text { received a CPI } \\
\text { and previously } \\
\text { received } \\
\text { platinum- } \\
\text { containing } \\
\text { chemotherapy }\end{array}$ & $\begin{array}{c}11.7 \\
\text { months }\end{array}$ & 5.8 months & $44 \%$ & 1.8 months & 7.6 months \\
\hline
\end{tabular}

PFS: progression-free survival. 


\begin{tabular}{|c|c|c|c|}
\hline Therapy & $\begin{array}{c}\text { Common grade } 3 \text { or greater } \\
\text { treatment-related adverse } \\
\text { events }\end{array}$ & Administration & $\begin{array}{l}\text { Biomarker testing } \\
\text { requirements }\end{array}$ \\
\hline $\begin{array}{l}\text { Immunotherapy } \\
\text { (pembrolizumab, } \\
\text { atezolizumab, avelumab } \\
\text { or durvalumab) }\end{array}$ & $\begin{array}{c}\text { Pneumonitis } \\
\text { Diarrhea } \\
\text { Fatigue } \\
\text { Anemia } \\
\text { Hypertension } \\
\text { Urinary tract infection } \\
\text { Asthenia } \\
\text { Increased AST, ALT and/or GGT }\end{array}$ & $\begin{array}{l}\text { Intravenous infusion } \\
\text { every } 2 \text { or } 3 \text { weeks }\end{array}$ & No testing required \\
\hline Erdafitinib $^{13}$ & $\begin{array}{l}\text { Hyponatremia } \\
\text { Stomatitis } \\
\text { Asthenia }\end{array}$ & $\begin{array}{c}\text { Daily oral dosing. } \\
\text { Dose adjustments were } \\
\text { made based on serum } \\
\text { phosphate levels at } \\
\text { day } 14\end{array}$ & $\begin{array}{c}\text { Tumour specimen must } \\
\text { have a confirmed FGFR } \\
\text { gene alteration }\end{array}$ \\
\hline Enfortumab vedotin ${ }^{14}$ & $\begin{array}{l}\text { Neutropenia } \\
\text { Anemia } \\
\text { Fatigue }\end{array}$ & $\begin{array}{l}\text { Intravenous infusion } \\
\text { on days } 1,8 \text { and } 15 \text { of } \\
\text { every } 28 \text {-day cycle }\end{array}$ & No testing required \\
\hline
\end{tabular}

